\title{
BIBECHANA
}

A Multidisciplinary Journal of Science, Technology and Mathematics

ISSN 2091-0762 (Print), 2382-5340 (0nline)

Journal homepage: http://nepjol.info/index.php/BIBECHANA

Publisher: Research Council of Science and Technology, Biratnagar, Nepal

\section{Design and development of shovel type-spring steel furrow opener for cultivator mounted seed metering mechanism}

\author{
Ajay Verma $^{1}$, Ankitesh Shrivastava ${ }^{2 *}$ \\ ${ }^{1}$ Farm Machinery \& Power Engineering, Indira Gandhi Agricultural University, Raipur (C.G.), India. \\ ${ }^{2}$ Production Engineering, Bhilai Institute of Technology, Durg (C.G.), India. \\ "Email: ankiteshrivastava@gmail.com
}

Article history: Received 20 October, 2017; Accepted 24 November, 2017

DOI: http://dx.doi.org/10.3126/bibechana.v15i0.18455

This work is licensed under the Creative Commons CC BY-NC License.

https://creativecommons.org/licenses/by-nc/4.0/

\section{cC) (i) (8)}

Abstract

The cultivator mounted seed metering mechanism consists of cultivator frame, tines, seed box, seed tubes, metering mechanism, power transmission unit, furrow opener and hitching attachments. The drawings of the developed machine were generated using CAD software and the machine was fabricated in the workshop of Faculty of Agricultural Engineering, IGAU, Raipur. Power was transmitted from ground wheel through sprocket-chain drive to the main shaft. At the average working speed of $3.8 \mathrm{~km} / \mathrm{h}$ of tractor drawn cultivator, depth of operation was found $129 \mathrm{~mm}$, average weed efficiency was found $76.42 \%$,effective field capacity was found $0.826 \mathrm{ha} / \mathrm{h}$ with field efficiency of $87.40 \%$. The cost of operation and energy requirement of cultivator was found to be Rs 387 per ha and $241 \mathrm{MJ} / \mathrm{ha}$. The Energy requirement for cultivator-cum-seed drill was found to be $454.18 \mathrm{MJ} / \mathrm{ha}$.

Keywords: Furrow opener, Cultivator; Metering device; Fluted roller; Seed tubes.

\section{Introduction}

In the trend of growth of power operated machinery, cultivators and seed drill are the equipment mostly used by farmers. Most of the farmers are having cultivators keeping in this mind the shape to this idea is given of a seed metering attachments to cultivator will be developed in workshop of Faculty of Agricultural Engineering. It will perform both tillage as well as sowing operation. This developed attachment will easily be attached to the existing cultivator, and consequently will minimise the energy and cost of operation. Baker (1976) investigated the performances of furrow openers including disc, chisel and hoe types in the lab. It was noted that germination was significantly higher by chisel $(77 \%)$ than hoe $(26 \%)$ and disc $(27 \%)$ that was mainly due to remaining moisture in the furrows. The developed machine could also be adopted as cultivator for secondary tillage operations and inter-culture operations by simply removing seed box with the help of nuts and bolts on the cultivator frame. 
Iqbal (1994) reported that the draft requirement of tillage implement has a great influence in design of tillage implements and deciding suitable tractor size and also concluded that draft of implement increases with increase in depth of ploughing. Damora (1995) observed that more compaction of furrow bottom and less seed scatter occurred with shoe type openers as compared to shovel and hoe type openers. The type and purpose of presowing tillage implement is many ranging in operations from breaking of soil to finishing the surface which consumes considerable time and energy resulting in delayed sowing with higher cost of cultivation. Laurel (1995) reported that at $150 \mathrm{~mm}$ working depth, the V-shaped sweep with pitch angle of 10 degree and the blade swept back at angle of 70 degrees performed good control of weeds. At this configuration, the sweep did not invert the soil. There was minimum soil disturbance, which was found adequate to drill the crop in the same operation. Sharma (2001) reported the performance of tractor drawn multi-crop ridge-furrow and flatbed seeding machine. It was capable of sowing 5-6 ha/day depending on type of crop sown. There was $30-40 \%$ saving of irrigation water with its use as ridge-seeder.

\section{Materials \& Methods}

\section{Furrow openers}

Reversible shovel type furrow openers were provided on the machine to help in sowing of crop. The furrow opener comprises of shovel, tine, boot and boot pipe to attach delivery tubes. The boot of opener was made out of $1.5 \mathrm{~mm}$ thick MS sheet it was welded to the tine and shovel assembly. Two holes each $10 \mathrm{~mm}$ diameter at a spacing of $50 \mathrm{~mm}$ were provided to fix the boot and opener using nuts and bolts (Fig. 1). One MS boot pipe of $25 \mathrm{~mm}$ external diameter and $150 \mathrm{~mm}$ length for seed was welded in the boot. Seed are received from the respective tubes and conveyed to deposits in to furrow. The developed furrow opener is shown in Fig. 3.

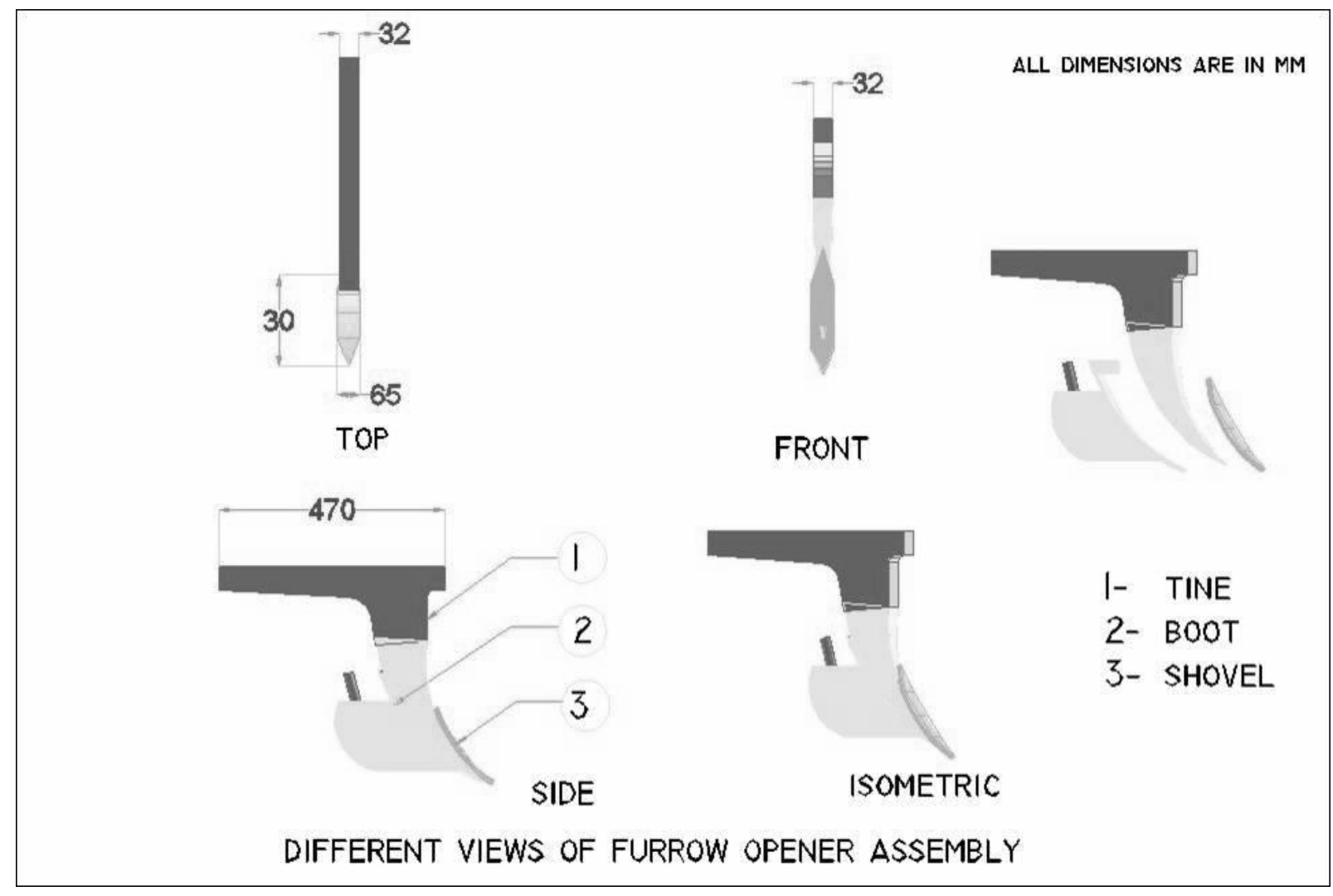

Fig. 1: Design developed for furrow opener. 


\section{Fluted roller type seed metering devices}

The metering mechanism for seed consisted of Standard die cast aluminum fluted roller (BIS: 6816 part I, II, III, IV) seed metering unit with 12 flute were used for seed metering. One square shaft of $16 \mathrm{~mm}$ size, and $2100 \mathrm{~mm}$ made up of mild steel were passed through fluted roller for rotating the roller. Rotation of fluted roller in housing, filled with seeds causes the seeds to flow out from roller housing in a continuous stream. The seed rate can be adjusted by controlling exposed length of flutes, which is in contact with seed .fairly accurate seed rate can be achieved for a variety of medium size seeds like paddy wheat and sunflower etc.

\section{Seed tubes}

Seed tubes were made of transparent plastic pipe according to distance between different fluted roller and furrow opener boot pipes. Each seed tube was attached to the seed distributor at one end the other end was attached to the boot at furrow opener. The length of the pipe has been taken according to the distance between different fluted rollers and furrow opener boot pipes. The time of fall of the seed through a tube is affected by the size and type of tube by the striking and bouncing of seeds against the wall of the seed tube. Transparent plastic tubes of $22 \mathrm{~mm}$ diameter and $2 \mathrm{~mm}$ thick were selected.

\section{Drive mechanism}

The chain and sprocket drive was used to transmit power from ground wheel to the metering device, where power is supplied to a number of rows. Selection of motorcycle chain of 0.5 inch $(16 \mathrm{~mm})$ pitch is adequate. A mild steel ground wheel provided with 12 spikes on the periphery of the wheel of $450 \mathrm{~mm}$ diameter has been used. On ground wheel shaft a 10 teeth sprocket is mounted and in another intermediate shaft 18 teeth sprocket is mounted. On the same shaft a 10 teeth sprocket is mounted which is connected to the seed metering fluted roller shaft through 18 teeth sprocket with chain. An idler was provided to adjust tension developed in chain (Fig. 2).

\section{Results \& Discussion}

\section{Design of shank of furrow opener}

Considering available draft of $345.6 \mathrm{Kg}$ exerted on the tip of furrow opener

Bending moment $=$ draft $\mathrm{x}$ ground clearance

$$
\begin{aligned}
= & 345.6 \times 50 \mathrm{~cm} \\
= & 17280 \mathrm{~kg}-\mathrm{cm} \\
& \text { Bending stress, } \mathrm{f}=\mathrm{MC} / \mathrm{I}
\end{aligned}
$$

where, $\mathrm{M}=$ Bending stress, $\mathrm{kg} / \mathrm{cm}^{2}$.

$$
\mathrm{I}=\text { Moment of inertia, } \mathrm{cm}^{4} \text {. }
$$

$\mathrm{C}=$ Distance from the neutral axis to the point at which stress is determined.

The section modulus of axis computed by using formula,

$$
\mathrm{Z}=\mathrm{I} / \mathrm{C}
$$

From (1) and (2)

$$
\mathrm{Z}=\mathrm{M} / \mathrm{f}
$$

Assuming bending stress equal to $1000 \mathrm{Kg} / \mathrm{cm}^{2}$,

$$
\begin{aligned}
& Z=17280 / 1000 \\
& Z=17.28 \mathrm{~cm}^{3}
\end{aligned}
$$

Section modulus of furrow opener is,

$$
\mathrm{Z}=\mathrm{bh}^{2} / 6
$$

The most assumed ratio of thickness to the width of shank is $b: h=1: 2$ to $1: 4$

Assuming $b: h=1: 2$

$$
\begin{aligned}
& 17.28=\mathrm{bh}^{2} / 6 \\
& b=29.59 \mathrm{~mm}
\end{aligned}
$$

Considering availability of material of standard size the thickness of shank selected is $32 \mathrm{~mm}$.

\section{Exposed length of fluted roller}


The volume of seed dropped per meter length of the row is given by-

Where, $\mathrm{s}=$ seed rate for crop in $\mathrm{kg} / \mathrm{ha}$

$$
\mathrm{Vs}=(\mathrm{s} \times \mathrm{r}) /(10 \rho)
$$

$\rho=$ bulk density of seed in $\mathrm{g} / \mathrm{cm}^{3}$

$\mathrm{r}=$ row spacing $\mathrm{m}$

The area of semi-circular flute is given by,

$$
\mathrm{A}_{\mathrm{f}}=\rho \mathrm{d}_{\mathrm{f}}^{2} / 8
$$

where $d_{f}=$ diameter of flute in $\mathrm{cm}$.

The delivered volume per revolution of the roller is given by,

$$
\mathrm{V}_{\mathrm{d}}=\mathrm{A}_{\mathrm{f}} \times \mathrm{N}_{\mathrm{f}} \times \mathrm{I}_{\mathrm{f}}
$$

where, $A_{f}=$ area of semi-circular flute in $\mathrm{cm}^{2}$

$\mathrm{N}_{\mathrm{f}}=$ number of flute

$\mathrm{I}_{\mathrm{f}}=$ exposed length of flute in $\mathrm{cm}$.

The number of revolutions of a fluted roller, $\mathrm{n}_{\mathrm{f}}$ is given by

$$
\mathrm{n}_{\mathrm{f}}=\mathrm{i} \times \mathrm{n}_{\mathrm{g}}
$$

Where, $i=$ transmission ratio

$\mathrm{n}_{\mathrm{g}}=$ number of revolutions of ground wheel.

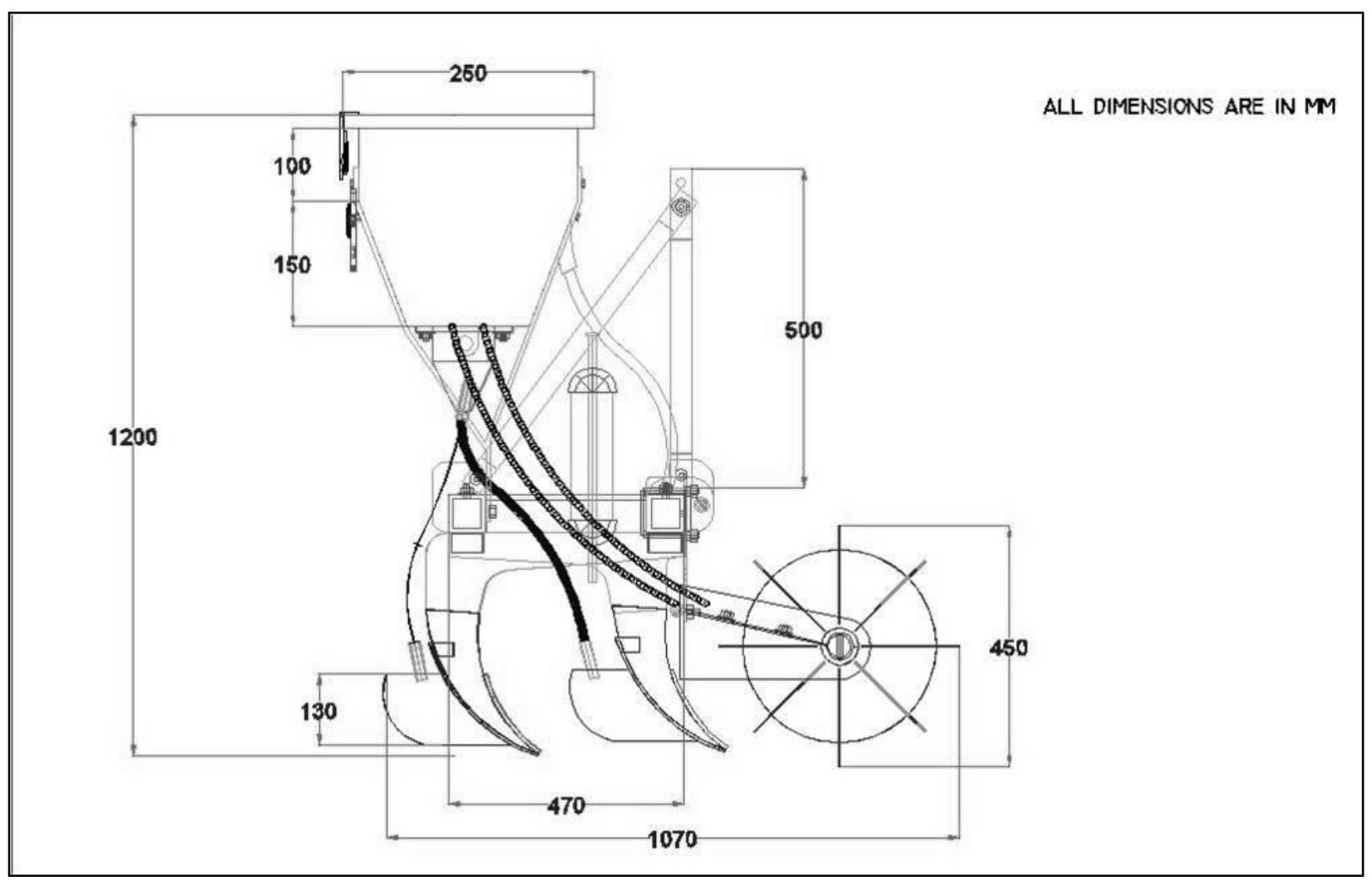

Fig. 2: Drive mechanism for the cultivator.

The distance, $\mathrm{D}_{\mathrm{g}}$ covered by the ground wheel per revolution is given by,

$$
D_{g}=\Pi \times d_{g}
$$

Where, $\mathrm{d}_{\mathrm{g}}=$ diameter of ground wheel in $\mathrm{m}$.

The volume of seed per meter traveled by the ground wheel is given by

$$
\mathrm{V}_{\mathrm{s}}=\mathrm{V}_{\mathrm{d}} \mathrm{i} / \Pi \mathrm{d}_{\mathrm{g}}
$$


The exposed length of the fluted roller is derived by combining equations (4) up to (8) as follows $\mathrm{I}_{\mathrm{f}}=\left(8 \times \mathrm{x} \times \mathrm{r} \times \mathrm{d}_{\mathrm{g}}\right) /\left(10 \times \pi \times \mathrm{d}_{\mathrm{f}}^{2} \times \mathrm{N}_{\mathrm{f}} \times \mathrm{i}\right)$
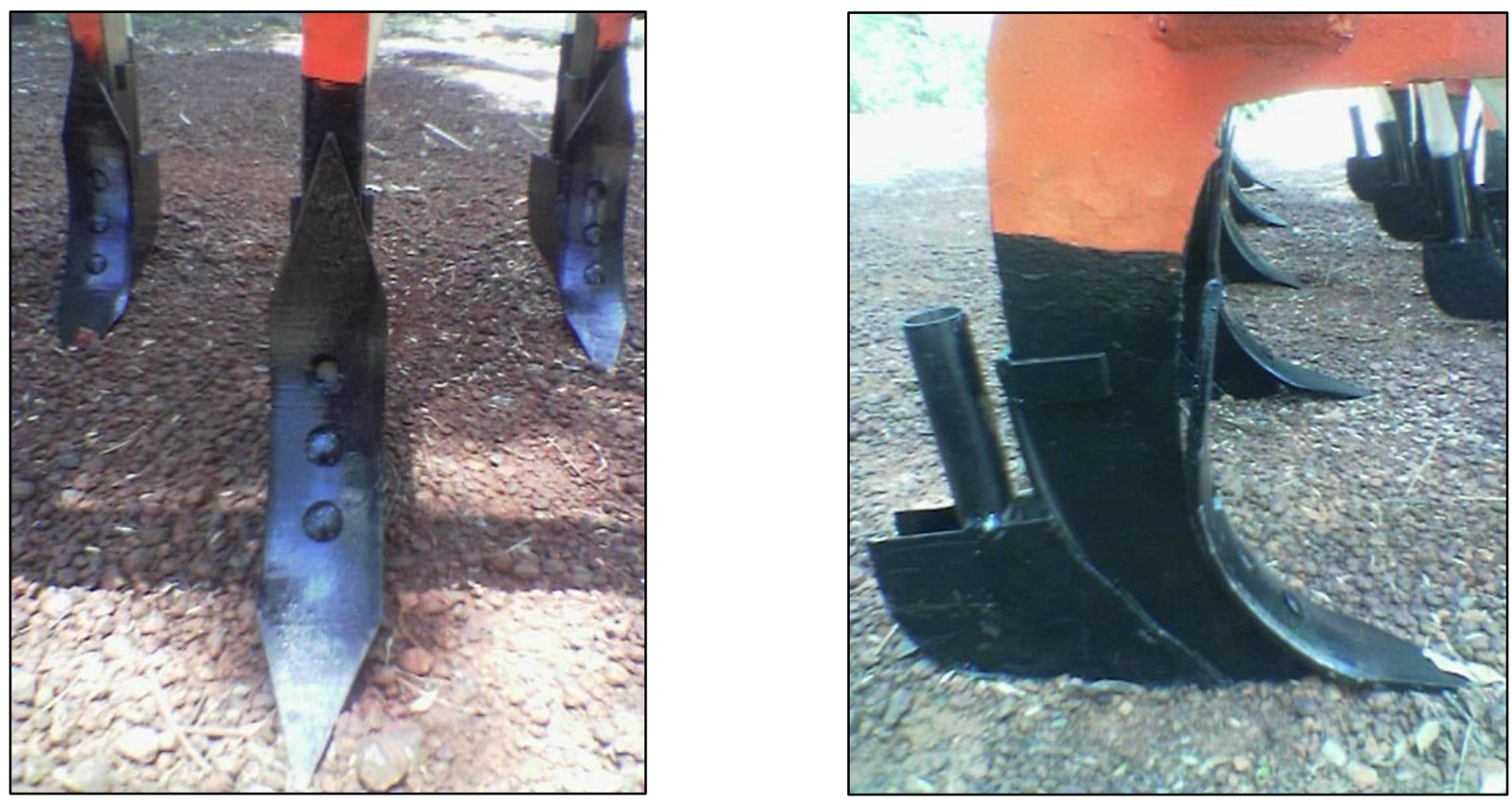

Fig. 3: Developed furrow opener.

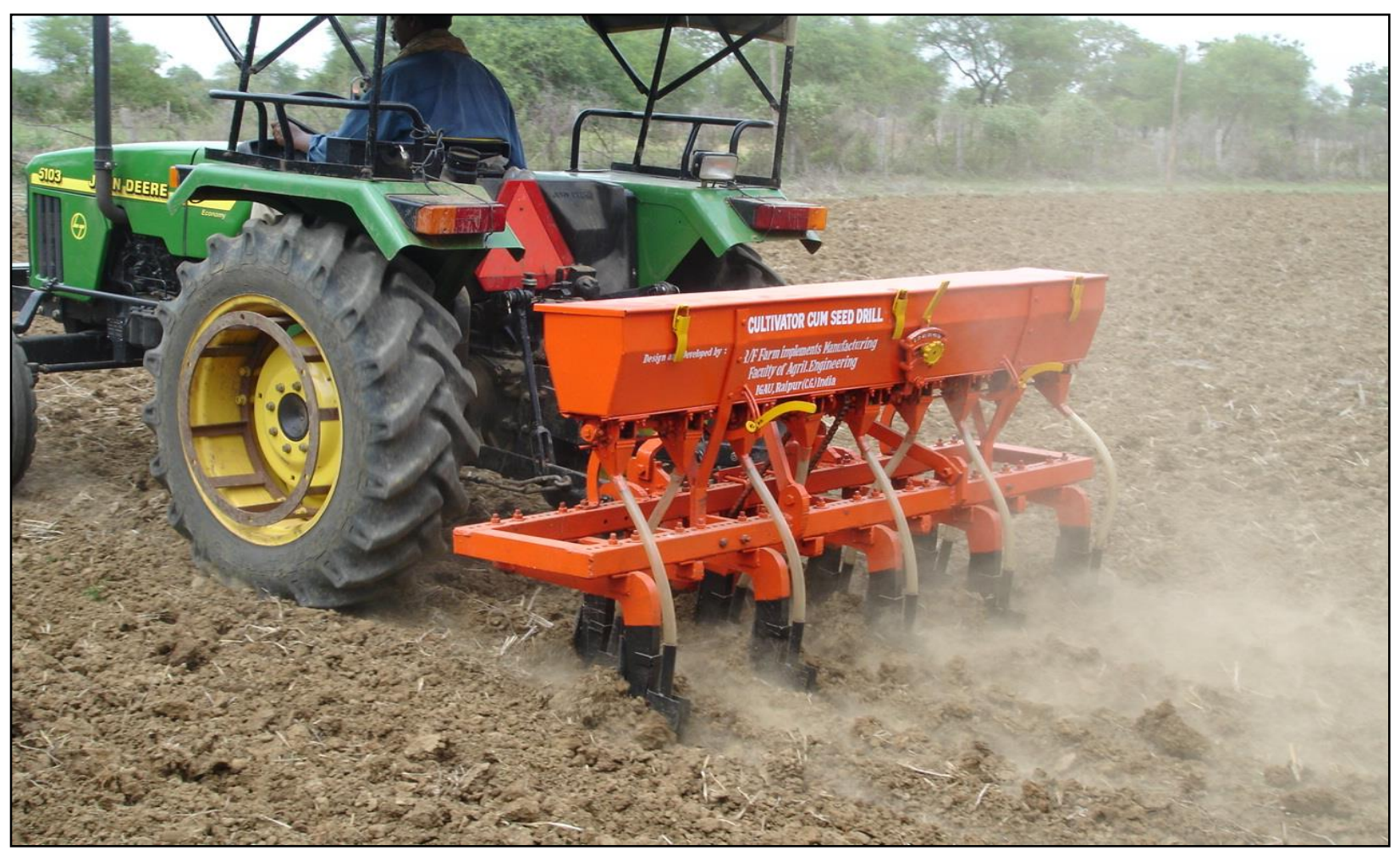

Fig. 4: Developed seed-drill in operation. 


\section{Conclusion}

The seed rate of cultivator-cum-seed drill was found to be $80.87 \mathrm{~kg} / \mathrm{ha}$ when seed drill was half filled and flute exposure was $14.9 \mathrm{~mm}$ and that of conventional seed drill was found to be $80.26 \mathrm{~kg} / \mathrm{ha}$. When seed drill was half filled and flute exposure was $13.8 \mathrm{~mm}$. The variation in dropping the seeds between the rows of cultivator-cum-seed drill was -3.05 to +3.1 for paddy and that of conventional seed drill was -2.02 to +2.02 respectively. The standard deviation for inter row variation for sowing paddy with cultivator-cum-seed drill was 0.46 with $\mathrm{CV}$ of $1.8 \%$ and for conventional seed drill was 0.41 and $1.5 \%$ respectively. The average speed of operation of cultivator-cum-seed drill was found $3.09 \mathrm{~km} / \mathrm{h}$ and that of conventional seed drill was $3.5 \mathrm{~km} / \mathrm{h}$. The average depth of seed placement with cultivator-cum-seed drill was found to be $57.8 \mathrm{~mm}$ and that of conventional seed drill was $60.6 \mathrm{~mm}$. The effective field capacity of the cultivator-cum seed drill was $0.537 \mathrm{ha} / \mathrm{h}$ with field efficiency 82.8 $\%$ as compared to conventional seed drill which was $0.596 \mathrm{ha} / \mathrm{h}$ and $82.32 \%$.

\section{References}

[1] C.J. Baker, Experiments relating to techniques for direct drilling of seeds into untilled dead turf, J. of Agricultural Engineering Research 21(1976) 133-144. doi.org/10.1016/0021-8634(76)90068-8.

[2] D. P. Darmora, K.P. Pandey, Evaluation of performance of furrow openers of combined seed and fertilizer drills. Soil \& Tillage Research 34 (1995) 127-139.

[3] M. Iqbal, M.S. Sabir, Md. Younis, A. H. Azhar, Draft requirements of selected tillage implements. AMA 25(1) (1994) 13-15.

[4] H. Laural Ortiz, An agricultural implement for non-inversion tillage in semi- arid regions. AMA 26(4) (1994) 22-24.

[5] D.N. Sharma, D.P. Kataria, V.P. Bahl, On farm trials of tractor drawn multicrop ridge-furrow and flat bed seeding machine for rain fed and irrigated conditions. Journal of agricultural engineering 38(1) (2001) 24-33. 